\title{
Prediction of passenger train using fuzzy time series and percentage change methods
}

\author{
Solikhin ${ }^{1}$, Septia Lutfi ${ }^{2}$, Purnomo ${ }^{3}$, Hardiwinoto ${ }^{4}$ \\ ${ }^{1,2}$ Department of Informatics Engineering, STMIK Himsya, Semarang, Indonesia \\ ${ }^{3}$ Department of Mechanical Engineering, Faculty of Engineering, University of Muhammadiyah Semarang, Indonesia \\ ${ }^{4}$ Department of Accounting, Faculty of Economics, University of Muhammadiyah Semarang, Indonesia
}

\begin{tabular}{l} 
Article Info \\
\hline Article history: \\
Received Jan 21, 2021 \\
Revised Aug 19, 2021 \\
Accepted Oct 15, 2021 \\
\hline
\end{tabular}

\section{Keywords:}

Double exponential smoothing

Forecasting

Fuzzy time series

Passenger train

Percentage change

\begin{abstract}
In the subject of railway operation, predicting railway passenger volume has always been a hot topic. Accurately forecasting railway passenger volume is the foundation for railway transportation companies to optimize transit efficiency and revenue. The goal of this research is to use a combination of the fuzzy time series approach based on the rate of change algorithm and the Holt double exponential smoothing method to forecast the number of train passengers. In contrast to prior investigations, we focus primarily on determining the next time period in this research. The fuzzy time series is employed as the forecasting basis, the rate of change is used to build the set of universes, and the Holt's double exponential smoothing method is utilized to forecast the following period in this case study. The number of railway passengers predicted for January 2020 is 38199, with a tiny average forecasting error rate of 0.89 percent and a mean square error of 131325 . It can also help rail firms identify future passenger needs, which can be used to decide whether to expand train cars or run new trains, as well as how to distribute tickets.
\end{abstract}

This is an open access article under the CC BY-SA license.

\section{Corresponding Author:}

Solikhin

Department of Informatics Engineering

STMIK Himsya

Jl. Raya Karanganyar Tugu Km. 12 No. 58 Semarang, Indonesia

Email: solikhin@stmik-himsya.ac.id

\section{INTRODUCTION}

Rail transit is a very viable option for meeting public transportation needs. The demand for a more efficient transportation system is growing. Transportation services are a fast-growing industry in a developing country like Indonesia. The planning and management of genuine railway business resources determine the quality of transportation services. Better serve the community and deal with rising transportation costs. Predicting passenger volume is very important in the field of rail transportation [1]. The key to increasing the operating efficiency and economic income of rail transport companies is the accurate and timely projection of the volume of rail passengers [1]. Accurate transportation volume predictions are critical for formulating strategies for future rail transportation growth, investment, and facility efficiency [2], as well as for local economic development, resource allocation, and cost reduction [3]. It also forms the basis for rail transport companies to determine whether to operate new trains [4], as well as how to allocate tickets [5] and taking ticket prices into consideration [6]. Prediction of the volume of train passengers on a large scale, not only includes predictions of passengers in one area but also passengers in all regions.

The requirement for public transportation services may be controlled sensibly by offering effective ground transportation services, therefore accurate forecasting is critical for every railway firm organization. 
Surprisingly, the number of train passengers at a station has been discovered to be a proxy for gauging a railway company's resource usage. It is obvious that accurate forecasting of the volume of railway passengers at the stations is critical to the efficient planning and distribution of railway company resources. Evaluating and forecasting the number of train passengers is a difficult and time-consuming task. According to past study, the results of fuzzy time series predictions are generally not obtained directly for the next time period.

Furthermore, the forecasting process and its results must be intelligible not only by rail transportation service company administrators, but also by individuals who make decisions based on the results. However, the current forecasting practice persists, in many ways, completely theoretical and statistically based approaches, notwithstanding the research that has been done to cope with complex time series data. To anticipate train passenger volume, It is vital to use soft computing-based algorithms that are scientifically sound and dependable. This soft computational approach should be able to deal with time series data that is complicated and create approximation values with a small error margin.

Soft computing approaches have been employed to solve prediction difficulties in recent years. In the application section, we describe a novel software system that was created using the presented theory. This covers linguistic study of time series and their trends. As a result of its ability to solve the forecasting issue in uncertain situations where historical data is incomplete or vague, fuzzy time series are now widely used in a variety of fields, including enrollment forecasting, stock index forecasting, temperature forecasting, and so on, with better forecasting results. Forecasting is the technique of projecting future performance based on previously collected data. In everyday life, forecasting plays a crucial role. The traditional time squence approach is a prominent forecasting method. The classical time series method, despite its widespread use, has a flaw: if the forecasted results are real numbers, what has been described cannot be understood. To circumvent this flaw, the fuzzy time series approach [7] is used. The fuzzy time series approach converts real-number anticipated values into linguistic values.

The goal of this research is to forecast the number of railway passengers using a combination of the fuzzy time series (FTS) and percentage change methods, which are prediction methods based on the percentage change of a datum over a period of time [8] and the classic double exponential smoothing Holt (DES Holt) method. The FTS is employed as the forecasting basis, percentage of change is used to build the set of universes, and the DES Holt method is used to forecast the following period in this case study. Thus it can be said that the proposed method has unique characteristic that is, it is a hybrid, in the sense that FTS modeling is combined simultaneously with statistical modeling (DES Holt).

In terms of prediction, numerous researchers recommend using the FTS approach. Song and Chissom [7] were the forerunners of the FTS concept, using it to model academic enrollment data at the University of Alabama [7], [9]-[21], predict temperature [22], [23], forecast the stock market index [24]-[35]. Other researchers have developed many improvements to the FTS prediction method, which addressed the following issues [16]: determining the effective interval length [15], [35]-[41], fuzzy logic relationship [42], and defuzzification methodology [21]. The use of fuzzy metric techniques in predictions [8], [43], [44], as well as the percentage change as the universe of speech [8], [44].

\section{RESEARCH METHOD}

\subsection{Fuzzy time series: a basic concept}

The first FTS definitions were presented in 1993 [45]. The following are the concepts of FTS. Let $U$ denote the discourse universe, where $U=\left\{u_{1}, u_{2}, \ldots u_{n}\right\} . A_{i}$ of $U$ is a fuzzy set defined by:

$$
A_{i}=f A_{i}\left(u_{1}\right) / u_{1}+f A_{i}\left(u_{2}\right) / u_{2}+\cdots A_{i}\left(u_{n}\right) / u_{n},
$$

where $f_{A}$ is the fuzzy set $A_{i}$ is membership function; $f_{A i}: U \rightarrow[0,1] . u_{k}$ is a component of the $A_{i}$ fuzzy set and $f_{A i}\left(u_{k}\right)$ is the degree to which $\mathrm{u}_{\mathrm{k}}$ belongs to $A_{i}, f_{A i}\left(u_{k}\right) \in[0,1]$ and $1<k<n$.

Definition 1. $Y(t)(t=\cdots, 0,1,2, \ldots)$, is a subset of $R$. Let $Y(t)$ denote the discourse universe as defined by the fuzzy set $f_{i}(t)$. If $F(y)$ is made up of $f_{1}(t), f_{2}(t)$, and so on, $F(t)$ is a FTS on $Y(u)(t=\ldots, 0,1,2, \ldots)$. Definition 2. If a fuzzy relationship $R(t-1, t)$ exists such that $F(t)=F(t-1) \times R(t-1, t)$ where $\times$ represents an operator, then $F(t)$ is said to be induced by $F(t-1)$.

Let $F(t)=A_{i}$ and $F(t-1)=A_{j}$. The relationship between $F(t)$ and $F(t-1)$ (referred to as a fuzzy logical relationship, FLR) can be denoted by $A_{i} \rightarrow A_{j}$; where $A_{i}$ is called the left-hand side (LHS) and $A_{j}$ the right-hand side (RHS) of the FLR.

Definition 3. Given two FLR on the LHS with the same fuzzy sets, $A_{i} \rightarrow A_{j 1}, A_{i} \rightarrow A_{j 2}$. Both FLR can be combined into FLRG (fuzzy logical relationship groups) $A_{i} \rightarrow A_{j 1}, A_{j 2}$. 


\subsection{The algorithm's key concepts}

\subsubsection{Procedure for event discretization}

In FTS theory, the discretization process reduces the complexity of the discourse world. This approach is typically used as a first step in preparing the universe of speech for numerical evaluation by tying events from different time periods together. Differences in time series data have been employed as the universe of discourse in several forecasting systems [46]. Time series data differences can improve forecasting accuracy. However, estimates of growing and decreasing rates of time series data cannot be made solely on the basis of disparities. As a result, the universe of discourse in our method is defined as the percentage of change (PoC) from time t to time $t+1$.

As $\operatorname{PoC}(t+1)=(X(t+1)-X(t)) X(t)$, where $X(t+1)$ is the value at time $t+1$ index and $X(t)$ is the actual value at time $t$ index, the event discretization function can be defined in such a way that its value at time $t$ index correlates with the occurrence of the event at a specific time in the future. PoC is the percentage change in value from time t to time $t+1$. Example: The PoC of period 2012/2 is calculated as (9515-10223)\10223, which equals -6.93 percent, as shown in Table 1. The PoC for the following year/month is calculated in the same way.

Table 1. Calculation example for PoC

\begin{tabular}{cccc}
\hline Year & Month & Time Series Data & PoC \\
\hline 2012 & 1 & 10223 & \\
2012 & 2 & 9515 & $-6.93 \%$ \\
2012 & 3 & 10787 & $13.37 \%$ \\
2012 & 4 & 9926 & $-7.98 \%$ \\
\hline
\end{tabular}

\subsubsection{Procedure for dividing frequency density}

We changed the approach for dividing the frequency density [8], [9], [43], [44] in this session to:

- Calculate the number of PoCs that fall in each interval.

- Determine the ranking based on the number of frequencies.

- Divide the interval by the biggest ranking minus one to find the interval.

- In the same manner, repeat for the next interval.

Table 2 shows sample data at intervals along the number of PoC. In Table 2, the interval $\{-15,-10\}$ has the highest PoC frequency. It is subdivided into three parts: $\{-10,-8.33\},\{-8.33,-6.67\}$, and $\{-6.67,-5\}$. Furthermore, the interval $\{-10,-5\}$ is the interval with the next highest frequency of data. It will be separated into two sections: $\{-10,-7.5\}$ and $\{-7.5,-5\}$. After that, leave the intervals $\{-5,0\}$ and $\{0,5\}$ unaltered.

Table 2. PoC frequency with interval

\begin{tabular}{ccc}
\hline Interval & Number of PoC & Ranking \\
\hline$\{-15,-10\}$ & 1 & 3 \\
$\{-10,-5\}$ & 4 & 1 \\
$\{-5,0\}$ & 1 & 3 \\
$\{0,5\}$ & 3 & 2 \\
\hline
\end{tabular}

\subsubsection{Define fuzzy set based on triangular membership function}

Based on the interval produced using the triangular membership function, defining fuzzy set $A_{j}=1,2,3,4, \ldots, n$. Then, to calculate the anticipated value of the percentage change, find the mean value at the interval obtained. Then, using (2), estimate the percentage change data using the triangle membership function.

$$
t_{j}=\left\{\begin{aligned}
\frac{1+0.5}{\frac{1}{a_{1}}+\frac{0.5}{a_{2}}} & \text {, if } j=1, \\
\frac{0.5+1+0.5}{0.5}+\frac{1}{a_{j}}+\frac{0.5}{a_{j+1}} & \text {, if } 2 \leq j \leq n-2, \\
\frac{0.5+1}{\frac{0.5}{a_{n-1}+\frac{1}{a_{n}}}} & \text {, if } j=n .
\end{aligned}\right.
$$

where $a_{j-1}, a_{j}, a_{j+1}$ are the mean of the fuzzy intervals of $x_{j}-1, x_{j}, x_{j}+1$ respectively. $t_{j}$ generates prediction of the percentage change in the number of train passengers from month to month. 
2.2.4. Determining the data value based on the forecasting results $t_{j} \rightarrow F(t)$

where: $x_{t-1}=$ actual data to $t-1$

\subsubsection{Determine the prediction for the next time period $t+1$}

The combination of methods using the DES Holt approach. The DES is a popular technique for predicting the trend of time series data using simple linear equations in business and economics [47]. Introduction A class of forecasting algorithms is described by the exponential smoothing (ES) method [48]. In corporate forecasting, ES is the most used family of forecasting models [49]. The double exponential smoothing (DES) is a trend time series extension of the exponential smoothing (ES) [50]. The calculate prediction for the next time period $t+1$ as shown in (3)-(7):

$$
\begin{aligned}
& S_{t}^{\prime}=\alpha X_{t}+(1-\alpha)\left(S_{t-1}^{\prime}+t_{t-1}\right) \\
& t_{t}=\beta\left(S_{t}^{\prime}-S_{t-1}^{\prime}\right)+(1-\beta) t_{t-1} \\
& F_{t+m}=S_{t}^{\prime}+t_{t m} \\
& S_{1}^{\prime}=X_{1} \\
& t_{1}=\frac{\left(x_{2}-x_{1}\right)+\left(x_{4}-x_{3}\right)}{2}
\end{aligned}
$$

where: $X_{t}=$ Actual data at time $\mathrm{t}$

$S_{t}^{\prime}=$ Single smoothing value

$t_{t}=$ Smoothing trend

$\alpha, \beta=$ Smoothing parameter between $0-1$

$F_{t+m}=$ Forecast value

$m=$ Future period

\subsubsection{Steps in the algorithm}

Historical data and graphs of the number of train passengers from January 2006 to December 2019 obtained from the statistics central agency (BPS) are shown in Figure 1. In order to solve the prediction issue in this case of the number of train passengers using the FTS and percentage change methods, the steps are carried out in 7 steps.

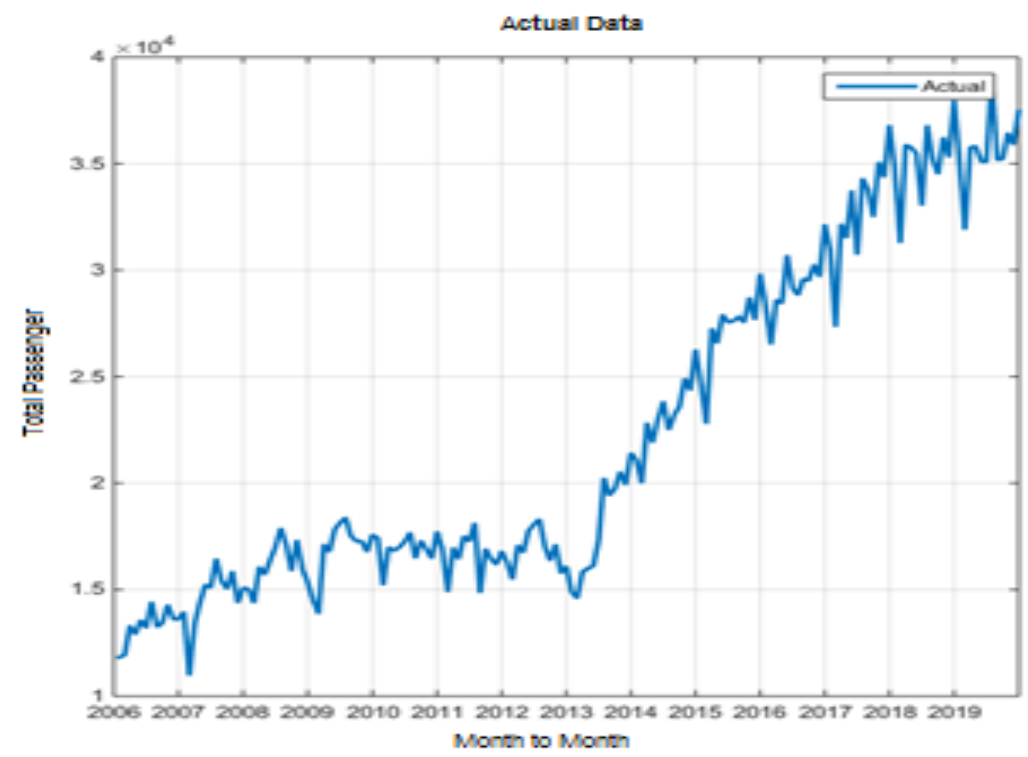

Figure 1. Graph of the actual train passengers data

Step 1: determining historical data of the actual number of train passengers in the form of time series data $X=x_{1}, x_{2}, x_{3}, x_{4}, x_{5}, \ldots, x_{n}$, then $X=[11828,11931,13314,12909,13575, \ldots, 37463]$. 
Step 2: determining the set of $U$ universe by:

a. Calculating the real data's percentage change on the number of train passengers using (8).

$$
d_{t}=\left(\frac{X_{i}-X_{i-1}}{X_{i-1}}\right) * 100
$$

b. Determining LL and UL from the results of the percentage change, then the obtained value of $L L$ is -21.4255 and $U L$ 23.5273. Thus $U$ can be determined using (9).

$$
U=\left\lceil L L-D_{1}, U L+D_{2}\right\rceil
$$

The values of $D_{1}$ and $D_{2}$ are positive integers to assist in defining the set of $U$ universe, so that the set of universes is defined $U=[-23.00,25.00]$.

c. Forming an interval class by calculating the number of intervals using (10).

$$
B=1+3.3 * \log (n)
$$

$\mathrm{n}=$ number of percentage change of data.

$B=1+3.3 * \log (167)=8.3350 \approx 8$

d. Calculating the length of the interval class using formula 11 .

$$
\begin{aligned}
& P=\frac{U L-L L}{B} \\
& P=\frac{25.00-(-23.00)}{8}=6.00
\end{aligned}
$$

Step 3: based on the result of forming the interval class on the set of universe, then the frequency of the percentage change of data included in each of these intervals was calculated and ranked based on the frequency, as shown in Table 3.

Table 3. Frequency and ranking

\begin{tabular}{ccc}
\hline Initial Interval Class & Frequency & Ranking \\
\hline$[-23.00,-17.00]$ & 2 & 1 \\
{$[-17.00,-11.00]$} & 3 & 2 \\
{$[-11.00,-5.00]$} & 23 & 5 \\
{$[-5.00,1.00]$} & 65 & 8 \\
{$[1.00,7.00]$} & 40 & 7 \\
{$[7.00,13.00]$} & 25 & 6 \\
{$[13.00,19.00]$} & 6 & 4 \\
{$[19.00,25.00]$} & 3 & 3 \\
\hline
\end{tabular}

Step 4: determining each fuzzy set $x_{i}$ based on the divided interval and fuzzification of the historical data of the number of train passengers, where the fuzzy set $x_{i}$ shows the linguistic value from month to month of the percentage change of data represented by the fuzzy set. Dividing the length of the interval based on the ranking of the data with the largest to the smallest frequency, for example $n=$ the largest frequency rating. The length of the interval is 6.00 , the ranking that is at the greatest frequency is 8 , then for the first interval it is divided into $n-1=8-1=7$ intervals with the same interval length, namely $6.00 / 7=0.8571$. The second interval is divided into $n-2=8-2=6$ intervals with the same interval length, namely $6.00 / 6=$ 1.00. The third interval is divided into $n-3=8-3=5$ intervals with the same interval length, namely $6.00 / 5=1.20$ and so on until the ninth last interval. The total number of intervals obtained becomes 29 interval classes. Then determining the mean value of each interval class as shown in Table 4.

Step 5: defuzzifying the fuzzy data shown in Table 5 (in Appendix).

Step 6: determining the value of the data based on the results of forecasting $t_{j} \rightarrow F(t)$ where $F(t)$ is the forecasting value of the data percentage change. The (12) is used to determine $F(t)$. The results of $F(t)$ are shown in Table 5.

$$
F(t)=\left(\frac{t_{j}}{100} * x_{t-1}\right)+x_{t-1}
$$

where: $x_{t-1}=$ actual data to $t-1$

whereas for $t+1$ forecasting used the classic double exponential smoothing holt (DES Holt) forecasting method with $\alpha=0.38$ and $\gamma=0.01$, the value of data smoothing in December 2019 was 36766 while the trend smoothing value was 145 using formula 3, 4, 5, 6, and 7. So that the forecast value for January 2020 is: 
$F(\operatorname{Jan} 2020)=s t+b t(m)=36766+145 *(1)=36911$ then the forecast results for January 2020 is: $F(\operatorname{Jan} 2020)=\left(\frac{1.9643}{100} * 37463\right)+37463=38199$.

Step 7: calculating the average forecasting error rate (AFER) and mean square error (MSE) [44] between real data and predicted results, namely the formulas 13 and 14 shown in Table 5 and Figure 2.

$$
\begin{aligned}
& \text { AFER }=\frac{\left(\frac{\left|A_{i}-F_{i}\right|}{A_{i}}\right)}{n} * 100 \% \\
& \operatorname{MSE}=\left(\sum\left(\mathrm{A}_{\mathrm{i}}-\mathrm{F}_{\mathrm{i}}\right)^{2}\right) / \mathrm{n}
\end{aligned}
$$

where: $\mathrm{i}=1 \ldots, \mathrm{n}$

Table 4. Frequency distribution, fuzzy set, and mean value

\begin{tabular}{ccr}
\hline Fuzzy & Intervals & Mean \\
\hline A1 & {$[-23.0000,-22.1429]$} & -22.5714 \\
A2 & {$[-22.1429,-21.2857]$} & -21.7143 \\
A3 & {$[-21.2857,-20.4286]$} & -20.8571 \\
A4 & {$[-20.4286,-19.5714]$} & -20.0000 \\
A5 & {$[-19.5714,-18.7143]$} & -19.1429 \\
A6 & {$[-18.7143,-17.8571]$} & -18.2857 \\
A7 & {$[-17.8571,-17.0000]$} & -17.4286 \\
A8 & {$[-17.0000,-16.0000]$} & -16.5000 \\
A9 & {$[-16.0000,-15.0000]$} & -15.5000 \\
A10 & {$[-15.0000,-14.0000]$} & -14.5000 \\
A11 & {$[-14.0000,-13.0000]$} & -13.5000 \\
A12 & {$[-13.0000,-12.0000]$} & -12.5000 \\
A13 & {$[-12.0000,-11.0000]$} & -11.5000 \\
A14 & {$[-11.0000,-9.8000]$} & -10.4000 \\
A15 & {$[-9.8000,-8.6000]$} & -9.2000 \\
A16 & {$[-8.6000,-7.4000]$} & -8.0000 \\
A17 & {$[-7.4000,-6.2000]$} & -6.8000 \\
A18 & {$[-6.2000,-5.0000]$} & -5.6000 \\
A19 & {$[-5.0000,-3.5000]$} & -4.2500 \\
A20 & {$[-3.5000,-2.0000]$} & -2.7500 \\
A21 & {$[-2.0000,-0.5000]$} & -1.2500 \\
A22 & {$[-0.5000,1.0000]$} & 0.2500 \\
A23 & {$[1.0000,3.0000]$} & 2.0000 \\
A24 & {$[3.0000,5.0000]$} & 4.0000 \\
A25 & {$[5.0000,7.0000]$} & 6.0000 \\
A26 & {$[7.0000,10.0000]$} & 8.5000 \\
A27 & {$[10.0000,13.0000]$} & 11.5000 \\
A28 & {$[13.0000,19.0000]$} & 16.0000 \\
A29 & {$[19.0000,25.0000]$} & 22.0000 \\
\hline & &
\end{tabular}

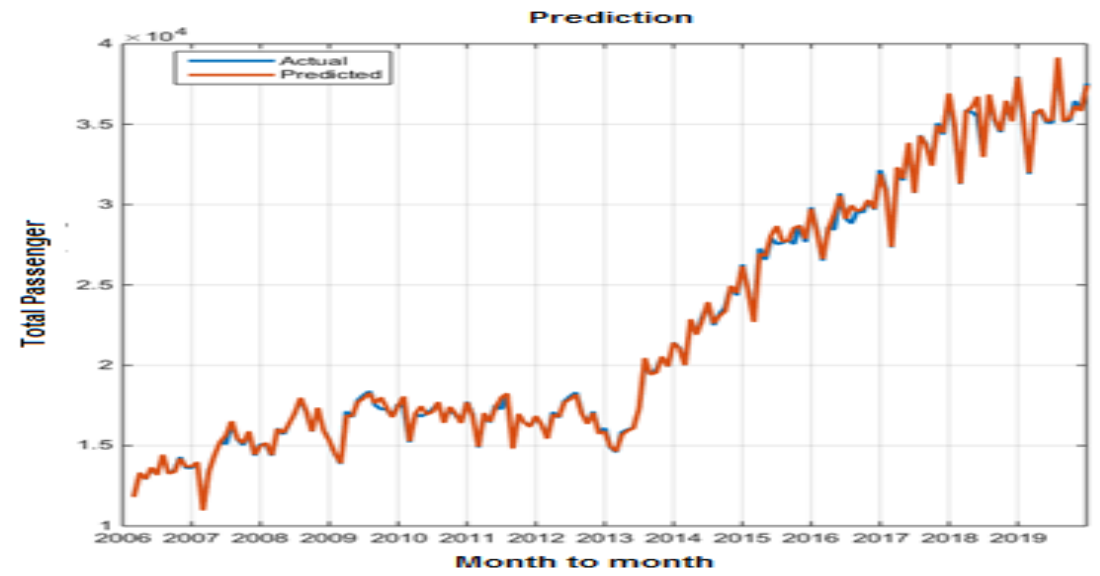

Figure 2. Prediction result graph 


\section{CONCLUSION}

The use of FTS and PC techniques, as well as a combination of DES Holt, has proven to be useful in predicting the number of railway passengers over the next time period. This may be seen in the prediction results for January 2020, which are 38199, with AFER=0.89 percent and MSE $=131325$. It can be utilized as decision assistance for railway management based on the aforesaid predicted results. Based on the aforementioned forecast results, railway management can use it as decision support to develop policies for the future period in terms of planning, resources, setting departure schedules, deciding ticket prices, adding train carriages, and adding tickets. Researchers will adapt these methods in the future to handle predictions in the same case study by constructing web-based applications and/or employing additional methods to anticipate data based on different intervals in order to improve accuracy.

\section{APPENDIX}

Table 5. Prediction results

\begin{tabular}{|c|c|c|c|c|c|c|c|c|}
\hline $\begin{array}{l}\text { Month } \\
\text { Year }\end{array}$ & $\begin{array}{c}\text { Passangers } \\
(A)_{i}\end{array}$ & $\begin{array}{c}\% \\
\text { Change }\left(d_{t}\right)\end{array}$ & $\begin{array}{l}\text { Fuzzy } \\
\text { Sets }\end{array}$ & $\begin{array}{l}\text { Prediction } \\
\%\left(t_{j}\right)\end{array}$ & $\begin{array}{l}\text { Forecast } \\
\qquad\left(F_{i}\right) t\end{array}$ & $A_{i}-F_{i}$ & AFER & MSE \\
\hline Jan06 & 11828 & - & - & - & - & - & - & - \\
\hline Feb06 & 11931 & 0.8708 & A22 & 0.5195 & 11889 & 42 & 0.3483 & 1726.8835 \\
\hline Mar06 & 13314 & 11.5917 & A27 & 11.2975 & 13279 & 35 & 0.2636 & 1231.5108 \\
\hline Apr06 & 12909 & -3.0419 & A20 & -2.2694 & 13012 & -103 & 0.7967 & 10578.0034 \\
\hline May06 & 13575 & 5.1592 & A 25 & 5.7063 & 13646 & -71 & 0.5203 & 4987.9602 \\
\hline Jun06 & 13203 & -2.7403 & A20 & -2.2694 & 13267 & -64 & 0.4842 & 4086.5635 \\
\hline Jul06 & 14433 & 9.3161 & A26 & 8.1813 & 14283 & 150 & 1.0380 & 22445.2185 \\
\hline Aug06 & 13255 & -8.1619 & A16 & -7.9090 & 13291 & -36 & 0.2753 & 1332.0249 \\
\hline Sep06 & 13436 & 1.3655 & A23 & 0.7619 & 13356 & 80 & 0.5955 & 6401.5189 \\
\hline Oct06 & 14290 & 6.3561 & A 25 & 5.7063 & 14203 & 87 & 0.6109 & 7621.6982 \\
\hline Nov06 & 13631 & -4.6116 & A19 & -3.9495 & 13726 & -95 & 0.6942 & 8953.3543 \\
\hline Dec06 & 13614 & -0.1247 & A22 & 0.5195 & 13702 & -88 & 0.6450 & 7710.6760 \\
\hline Jan07 & 13960 & 2.5415 & A23 & 0.7619 & 13718 & 242 & 1.7355 & 58696.8138 \\
\hline Feb07 & 10969 & -21.4255 & A2 & -21.6974 & 10931 & 38 & 0.3460 & 1440.7369 \\
\hline Mar07 & 13409 & 22.2445 & A29 & 26.0741 & 13829 & -420 & 3.1327 & 176454.3844 \\
\hline Apr07 & 14415 & 7.5024 & A26 & 8.1813 & 14506 & -91 & 0.6315 & 8287.6048 \\
\hline May07 & 15232 & 5.6677 & A 25 & 5.7063 & 15238 & -6 & 0.0365 & 30.9390 \\
\hline Jun07 & 15104 & -0.8403 & A21 & 1.9643 & 15531 & -427 & 2.8284 & 182499.8772 \\
\hline Jul07 & 16454 & 8.9380 & A26 & 8.1813 & 16340 & 114 & 0.6946 & 13062.1934 \\
\hline Aug07 & 15419 & -6.2903 & A 17 & -6.6924 & 15353 & 66 & 0.4292 & 4379.0085 \\
\hline Sep07 & 15033 & -2.5034 & A20 & -2.2694 & 15069 & -36 & 0.2400 & 1301.6315 \\
\hline Oct07 & 15866 & 5.5411 & A25 & 5.7063 & 15891 & -25 & 0.1565 & 616.3887 \\
\hline Nov07 & 14391 & -9.2966 & A 15 & -9.1211 & 14419 & -28 & 0.1935 & 775.6801 \\
\hline Dec07 & 15084 & 4.8155 & A24 & 3.4286 & 14884 & 200 & 1.3232 & 39837.9035 \\
\hline Jan08 & 15027 & -0.3779 & A22 & 0.5195 & 15162 & -135 & 0.9008 & 18321.9273 \\
\hline Feb08 & 14378 & -4.3189 & A19 & -3.9495 & 14434 & -56 & 0.3861 & 3081.8759 \\
\hline Mar08 & 16071 & 11.7749 & A27 & 11.2975 & 16002 & 69 & 0.4271 & 4711.8030 \\
\hline Apr08 & 15711 & -2.2401 & A20 & -2.2694 & 15706 & 5 & 0.0300 & 22.2641 \\
\hline May08 & 16363 & 4.1500 & A24 & 3.4286 & 16250 & 113 & 0.6926 & 12845.3232 \\
\hline Jun08 & 17010 & 3.9540 & A24 & 3.4286 & 16924 & 86 & 0.5055 & 7393.0638 \\
\hline Jul08 & 17887 & 5.1558 & A 25 & 5.7063 & 17981 & -94 & 0.5235 & 8768.5637 \\
\hline Aug08 & 17108 & -4.3551 & A19 & -3.9495 & 17181 & -73 & 0.4241 & 5264.9666 \\
\hline Sep08 & 15879 & -7.1838 & A17 & -6.6924 & 15963 & -84 & 0.5294 & 7065.6406 \\
\hline Oct08 & 17337 & 9.1819 & A26 & 8.1813 & 17178 & 159 & 0.9164 & 25244.2986 \\
\hline Nov08 & 15973 & -7.8676 & A16 & -7.9090 & 15966 & 7 & 0.0449 & 51.5504 \\
\hline Dec08 & 15332 & -4.0130 & A19 & -3.9495 & 15342 & -10 & 0.0662 & 103.0784 \\
\hline Jan09 & 14494 & -5.4657 & A18 & -5.4091 & 14503 & -9 & 0.0599 & 75.3133 \\
\hline Feb09 & 13869 & -4.3121 & A19 & -3.9495 & 13922 & -53 & 0.3790 & 2763.1074 \\
\hline Mar09 & 17132 & 23.5273 & A 29 & 26.0741 & 17485 & -353 & 2.0617 & 124759.2597 \\
\hline Apr09 & 16775 & -2.0838 & A20 & -2.2694 & 16743 & 32 & 0.1896 & 1011.0514 \\
\hline May09 & 17824 & 6.2534 & A 25 & 5.7063 & 17732 & 92 & 0.5149 & 8421.5827 \\
\hline Jun09 & 18143 & 1.7897 & A23 & 0.7619 & 17960 & 183 & 1.0097 & 33561.5265 \\
\hline Jul09 & 18385 & 1.3338 & A23 & 0.7619 & 18281 & 104 & 0.5644 & 10767.7098 \\
\hline Aug09 & 17527 & -4.6668 & A19 & -3.9495 & 17659 & -132 & 0.7525 & 17395.4414 \\
\hline Sep09 & 17281 & -1.4035 & A21 & 1.9643 & 17871 & -590 & 3.4158 & 348430.9591 \\
\hline Oct09 & 17281 & 0.0000 & A22 & 0.5195 & 17371 & -90 & 0.5195 & 8058.9243 \\
\hline Nov09 & 16778 & -2.9107 & A20 & -2.2694 & 16889 & -111 & 0.6605 & 12281.4115 \\
\hline Dec09 & 17581 & 4.7860 & A24 & 3.4286 & 17353 & 228 & 1.2955 & 51872.0474 \\
\hline Jan10 & 17424 & -0.8930 & A21 & 1.9643 & 17926 & -502 & 2.8830 & 252346.6025 \\
\hline Feb10 & 15207 & -12.7238 & A12 & -12.4599 & 15253 & -46 & 0.3024 & 2114.8064 \\
\hline Mar10 & 16992 & 11.7380 & A 27 & 11.2975 & 16925 & 67 & 0.3942 & 4487.1421 \\
\hline Apr10 & 16832 & -0.9416 & A21 & 1.9643 & 17326 & -494 & 2.9335 & 243810.2716 \\
\hline
\end{tabular}


Table 5. Prediction results (continue)

\begin{tabular}{|c|c|c|c|c|c|c|c|c|}
\hline $\begin{array}{c}\text { Month } \\
\text { Year }\end{array}$ & $\begin{array}{c}\text { Passangers } \\
(A)_{i}\end{array}$ & $\begin{array}{c}\% \\
\text { Change }\left(d_{t}\right)\end{array}$ & $\begin{array}{c}\text { Fuzzy } \\
\text { Sets }\end{array}$ & $\begin{array}{c}\text { Prediction } \\
\%\left(t_{j}\right) \\
\end{array}$ & $\begin{array}{l}\text { Forecast } \\
\left(F_{i}\right) t\end{array}$ & $A_{i}-F_{i}$ & AFER & MSE \\
\hline May10 & 16988 & 0.9268 & A22 & 0.5195 & 16919 & 69 & 0.4036 & 4700.6050 \\
\hline Jun10 & 17259 & 1.5952 & A23 & 0.7619 & 17117 & 142 & 0.8203 & 20041.3793 \\
\hline Jul10 & 17680 & 2.4393 & A23 & 0.7619 & 17390 & 290 & 1.6375 & 83811.8805 \\
\hline Aug10 & 16477 & -6.8043 & A17 & -6.6924 & 16497 & -20 & 0.1200 & 391.1142 \\
\hline Sep10 & 17301 & 5.0009 & A25 & 5.7063 & 17417 & -116 & 0.6718 & 13508.4976 \\
\hline Oct10 & 16908 & -2.2715 & A20 & -2.2694 & 16908 & 0 & 0.0022 & 0.1352 \\
\hline Nov10 & 16469 & -2.5964 & A20 & -2.2694 & 16524 & -55 & 0.3357 & 3056.5934 \\
\hline Dec10 & 17733 & 7.6750 & A26 & 8.1813 & 17816 & -83 & 0.4702 & 6953.1214 \\
\hline Jan11 & 16891 & -4.7482 & A19 & -3.9495 & 17033 & -142 & 0.8386 & 20062.5293 \\
\hline Feb11 & 14890 & -11.8465 & A13 & -11.4264 & 14961 & -71 & 0.4766 & 5036.2833 \\
\hline Mar11 & 16978 & 14.0228 & A28 & 15.5394 & 17204 & -226 & 1.3300 & 50989.8016 \\
\hline Apr11 & 16441 & -3.1629 & A20 & -2.2694 & 16593 & -152 & 0.9227 & 23012.2445 \\
\hline May11 & 17522 & 6.5750 & A 25 & 5.7063 & 17379 & 143 & 0.8151 & 20399.8957 \\
\hline Jun11 & 17265 & -1.4667 & A21 & 1.9643 & 17866 & -601 & 3.4821 & 361420.0291 \\
\hline Jul11 & 18132 & 5.0217 & A25 & 5.7063 & 18250 & -118 & 0.6518 & 13969.2683 \\
\hline Aug11 & 14846 & -18.1227 & A6 & -18.2656 & 14820 & 26 & 0.1746 & 671.7734 \\
\hline Sep11 & 16921 & 13.9768 & A28 & 15.5394 & 17153 & -232 & 1.3709 & 53810.9629 \\
\hline Oct11 & 16461 & -2.7185 & A20 & -2.2694 & 16537 & -76 & 0.4616 & 5774.6992 \\
\hline Nov11 & 16179 & -1.7131 & A21 & 1.9643 & 16784 & -605 & 3.7415 & 366437.8697 \\
\hline Dec11 & 16811 & 3.9063 & A24 & 3.4286 & 16734 & 77 & 0.4598 & 5973.9756 \\
\hline Jan12 & 16283 & -3.1408 & A20 & -2.2694 & 16429 & -146 & 0.8996 & 21458.6767 \\
\hline Feb12 & 15490 & -4.8701 & A19 & -3.9495 & 15640 & -150 & 0.9678 & 22472.8367 \\
\hline Mar12 & 17090 & 10.3292 & A 27 & 11.2975 & 17240 & -150 & 0.8776 & 22495.7546 \\
\hline Apr12 & 16746 & -2.0129 & A20 & -2.2694 & 16702 & 44 & 0.2618 & 1922.2856 \\
\hline May12 & 17771 & 6.1209 & A25 & 5.7063 & 17702 & 69 & 0.3907 & 4819.6927 \\
\hline Jun12 & 18062 & 1.6375 & A23 & 0.7619 & 17906 & 156 & 0.8615 & 24211.9396 \\
\hline Jul12 & 18309 & 1.3675 & A23 & 0.7619 & 18200 & 109 & 0.5974 & 11965.0167 \\
\hline Aug12 & 17056 & -6.8436 & A17 & -6.6924 & 17084 & -28 & 0.1623 & 766.2466 \\
\hline Sep12 & 16368 & -4.0338 & A19 & -3.9495 & 16382 & -14 & 0.0879 & 206.7873 \\
\hline Oct12 & 17127 & 4.6371 & A24 & 3.4286 & 16929 & 198 & 1.1550 & 39129.3890 \\
\hline Nov12 & 15773 & -7.9056 & A16 & -7.9090 & 15772 & 1 & 0.0036 & 0.3260 \\
\hline Dec12 & 16104 & 2.0985 & A23 & 0.7619 & 15893 & 211 & 1.3091 & 44447.0644 \\
\hline Jan13 & 14900 & -7.4764 & A16 & -7.9090 & 14830 & 70 & 0.4675 & 4852.8136 \\
\hline Feb13 & 14594 & -2.0537 & A20 & -2.2694 & 14562 & 32 & 0.2203 & 1033.2097 \\
\hline Mar13 & 15826 & 8.4418 & A26 & 8.1813 & 15788 & 38 & 0.2402 & 1445.1252 \\
\hline Apr13 & 16000 & 1.0995 & A23 & 0.7619 & 15947 & 53 & 0.3339 & 2853.7941 \\
\hline May13 & 16113 & 0.7063 & $\mathrm{~A} 22$ & 0.5195 & 16083 & 30 & 0.1855 & 892.9961 \\
\hline Jun13 & 17301 & 7.3729 & A26 & 8.1813 & 17431 & -130 & 0.7529 & 16967.6149 \\
\hline Jul13 & 20245 & 17.0164 & A 28 & 15.5394 & 19989 & 256 & 1.2622 & 65299.1872 \\
\hline Aug13 & 19423 & -4.0603 & A19 & -3.9495 & 19445 & -22 & 0.1155 & 503.1867 \\
\hline Sep13 & 19738 & 1.6218 & A23 & 0.7619 & 19571 & 167 & 0.8462 & 27894.0743 \\
\hline Oct13 & 20534 & 4.0328 & A24 & 3.4286 & 20415 & 119 & 0.5808 & 14225.0123 \\
\hline Nov13 & 19919 & -2.9950 & A20 & -2.2694 & 20068 & -149 & 0.7480 & 22200.1946 \\
\hline Dec13 & 21417 & 7.5205 & A26 & 8.1813 & 21549 & -132 & 0.6147 & 17329.5404 \\
\hline Jan14 & 21092 & -1.5175 & A21 & 1.9643 & 21838 & -746 & 3.5354 & 556055.2653 \\
\hline Feb14 & 19998 & -5.1868 & A18 & -5.4091 & 19951 & 47 & 0.2344 & 2198.2279 \\
\hline Mar14 & 22836 & 14.1914 & A28 & 15.5394 & 23106 & -270 & 1.1804 & 72662.1693 \\
\hline Apr14 & 21908 & -4.0638 & A19 & -3.9495 & 21934 & -26 & 0.1191 & 681.2786 \\
\hline May14 & 22988 & 4.9297 & A24 & 3.4286 & 22659 & 329 & 1.4306 & 108154.5990 \\
\hline Jun14 & 23840 & 3.7063 & A24 & 3.4286 & 23776 & 64 & 0.2678 & 4075.5582 \\
\hline Jul14 & 22500 & -5.6208 & A18 & -5.4091 & 22550 & -50 & 0.2243 & 2547.5181 \\
\hline Aug14 & 23199 & 3.1067 & A24 & 3.4286 & 23271 & -72 & 0.3122 & 5245.8840 \\
\hline Sep14 & 23593 & 1.6983 & A23 & 0.7619 & 23376 & 217 & 0.9208 & 47195.6764 \\
\hline Oct14 & 24923 & 5.6373 & A25 & 5.7063 & 24939 & -16 & 0.0653 & 265.2320 \\
\hline Nov14 & 24356 & -2.2750 & A20 & -2.2694 & 24357 & -1 & 0.0057 & 1.9389 \\
\hline Dec14 & 26275 & 7.8790 & A26 & 8.1813 & 26349 & -74 & 0.2803 & 5424.0133 \\
\hline Jan 15 & 24676 & -6.0856 & A18 & -5.4091 & 24854 & -178 & 0.7204 & 31599.1873 \\
\hline Feb15 & 22790 & -7.6431 & A16 & -7.9090 & 22724 & 66 & 0.2879 & 4305.9719 \\
\hline Mar15 & 27267 & 19.6446 & A29 & 26.0741 & 28732 & -1465 & 5.3738 & 2147047.0990 \\
\hline Apr15 & 26565 & -2.5745 & A20 & -2.2694 & 26648 & -83 & 0.3132 & 6921.7822 \\
\hline May15 & 27910 & 5.0631 & A25 & 5.7063 & 28081 & -171 & 0.6122 & 29198.9495 \\
\hline Jun15 & 27562 & -1.2469 & A21 & 1.9643 & 28458 & -896 & 3.2517 & 803232.1968 \\
\hline Jul15 & 27612 & 0.1814 & A22 & 0.5195 & 27705 & -93 & 0.3375 & 8682.3919 \\
\hline Aug15 & 27796 & 0.6664 & A22 & 0.5195 & 27755 & 41 & 0.1459 & 1645.1871 \\
\hline Sep15 & 27549 & -0.8886 & A21 & 1.9643 & 28342 & -793 & 2.8785 & 628837.7974 \\
\hline Oct15 & 28718 & 4.2433 & A24 & 3.4286 & 28494 & 224 & 0.7816 & 50383.6272 \\
\hline Nov15 & 27669 & -3.6528 & A19 & -3.9495 & 27584 & 85 & 0.3079 & 7260.0493 \\
\hline Dec15 & 29831 & 7.8138 & A26 & 8.1813 & 29933 & -102 & 0.3409 & 10342.0347 \\
\hline Jan16 & 28358 & -4.9378 & A19 & -3.9495 & 28653 & -295 & 1.0397 & 86928.6133 \\
\hline Feb16 & 26510 & -6.5167 & A17 & -6.6924 & 26460 & 50 & 0.1880 & 2484.2384 \\
\hline
\end{tabular}


Table 5. Prediction results (continue)

\begin{tabular}{|c|c|c|c|c|c|c|c|c|}
\hline $\begin{array}{l}\text { Month } \\
\text { Year }\end{array}$ & $\begin{array}{c}\text { Passangers } \\
(A)_{i}\end{array}$ & $\begin{array}{c}\% \\
\text { Change }\left(d_{t}\right)\end{array}$ & $\begin{array}{c}\text { Fuzzy } \\
\text { Sets }\end{array}$ & $\begin{array}{c}\text { Prediction } \\
\%\left(t_{j}\right) \\
\end{array}$ & $\begin{array}{l}\text { Forecast } \\
\left(F_{i}\right) t\end{array}$ & $A_{i}-F_{i}$ & AFER & MSE \\
\hline Mar16 & 28617 & 7.9479 & A26 & 8.1813 & 28679 & -62 & 0.2162 & 3828.3955 \\
\hline Apr16 & 28435 & -0.6360 & A21 & 1.9643 & 29179 & -744 & 2.6169 & 553714.1646 \\
\hline May 16 & 30703 & 7.9761 & A26 & 8.1813 & 30761 & -58 & 0.1901 & 3406.4595 \\
\hline Jun16 & 29159 & -5.0288 & A18 & -5.4091 & 29042 & 117 & 0.4004 & 13631.2403 \\
\hline Jul16 & 28831 & -1.1249 & A21 & 1.9643 & 29732 & -901 & 3.1243 & 811379.6655 \\
\hline Aug16 & 29588 & 2.6256 & A23 & 0.7619 & 29051 & 537 & 1,8161 & 288729.0843 \\
\hline Sep16 & 29516 & -0.2433 & A22 & 0.5195 & 29742 & -226 & 0.7647 & 50942.3129 \\
\hline Oct16 & 30263 & 2.5308 & A23 & 0.7619 & 29741 & 522 & 1.7253 & 272605.2430 \\
\hline Nov16 & 29690 & -1.8934 & A21 & 1.9643 & 30857 & -1167 & 3.9321 & 1362943.8739 \\
\hline Dec16 & 32150 & 8.2856 & A26 & 8.1813 & 32119 & 31 & 0.0963 & 958.4760 \\
\hline Jan17 & 30949 & -3.7356 & A19 & -3.9495 & 30880 & 69 & 0.2221 & 4726.7536 \\
\hline Feb17 & 27342 & -11.6547 & A13 & -11.4264 & 27413 & -71 & 0.2584 & 4990.4990 \\
\hline Mar17 & 32170 & 17.6578 & A28 & 15.5394 & 31591 & 579 & 1.8005 & 335508.4622 \\
\hline Apr17 & 31502 & -2.0765 & A 20 & -2.2694 & 31440 & 62 & 0.1970 & 3852.9846 \\
\hline May 17 & 33745 & 7.1202 & A26 & 8.1813 & 34079 & -334 & 0.9906 & 111747.5790 \\
\hline Jun17 & 30723 & -8.9554 & A15 & -9.1211 & 30667 & 56 & 0.1820 & 3125.3770 \\
\hline Jul17 & 34310 & 11.6753 & A27 & 11.2975 & 34194 & 116 & 0.3383 & 13470.6038 \\
\hline Aug17 & 33791 & -1.5127 & A21 & 1.9643 & 34984 & -1193 & 3.5304 & 1423121.4153 \\
\hline Sep17 & 32498 & -3.8265 & A19 & -3.9495 & 32456 & 42 & 0.1279 & 1727.4022 \\
\hline Oct17 & 35070 & 7.9143 & A26 & 8.1813 & 35157 & -87 & 0.2474 & 7529.5272 \\
\hline Nov17 & 34361 & -2.0217 & A 20 & -2.2694 & 34274 & 87 & 0.2529 & 7549.1064 \\
\hline Dec17 & 36807 & 7.1185 & A26 & 8.1813 & 37172 & -365 & 0.9922 & 133364.6624 \\
\hline Jan18 & 34717 & -5.6783 & A18 & -5.4091 & 34816 & -99 & 0.2854 & 9816.1021 \\
\hline Feb18 & 31278 & -9.9058 & A14 & -10.3103 & 31138 & 140 & 0.4490 & 19719.7005 \\
\hline Mar18 & 35875 & 14.6972 & A28 & 15.5394 & 36138 & -263 & 0.7342 & 69378.4500 \\
\hline Apr18 & 35754 & -0.3373 & A22 & 0.5195 & 36061 & -307 & 0.8597 & 94472.5109 \\
\hline May 18 & 35482 & -0.7608 & A 21 & 1.9643 & 36456 & -974 & 2.7459 & 949281.5670 \\
\hline Jun18 & 33030 & -6.9105 & A17 & -6.6924 & 33107 & -77 & 0.2343 & 5988.9705 \\
\hline Jul18 & 36800 & 11.4139 & A 27 & 11.2975 & 36762 & 38 & 0.1044 & 1476.7991 \\
\hline Aug18 & 35190 & -4.3750 & A19 & -3.9495 & 35347 & -157 & 0.4450 & 24523.1591 \\
\hline Sep18 & 34504 & -1.9494 & A 21 & 1.9643 & 35881 & -1377 & 3.9915 & 1896768.6523 \\
\hline Oct18 & 36236 & 5.0197 & A 25 & 5.7063 & 36473 & -237 & 0.6538 & 56121.4592 \\
\hline Nov18 & 35298 & -2.5886 & A20 & -2.2694 & 35414 & -116 & 0.3276 & 13375.6092 \\
\hline Dec18 & 37965 & 7.5557 & A26 & 8.1813 & 38186 & -221 & 0.5817 & 48774.9222 \\
\hline Jan19 & 35122 & -7.4885 & A 16 & -7.9090 & 34962 & 160 & 0.4545 & 25486.2888 \\
\hline Feb19 & 31899 & -9.1766 & A15 & -9.1211 & 31918 & -19 & 0.0611 & 380.1640 \\
\hline Mar19 & 35751 & 12.0756 & A27 & 11.2975 & 35503 & 248 & 0.6943 & 61605.2729 \\
\hline Apr19 & 35809 & 0.1622 & A 22 & 0.5195 & 35937 & -128 & 0.3567 & 16312.3096 \\
\hline May 19 & 35102 & -1.9744 & A21 & 1.9643 & 36512 & -1410 & 4.0180 & 1989203.2630 \\
\hline Jun19 & 35090 & -0.0342 & A22 & 0.5195 & 35284 & -194 & 0.5539 & 37771.2309 \\
\hline Jul19 & 39035 & 11.2425 & A 27 & 11.2975 & 39054 & -19 & 0.0494 & 372.4810 \\
\hline Aug19 & 35189 & -9.8527 & A14 & -10.3103 & 35010 & 179 & 0.5076 & 31907.1068 \\
\hline Sep19 & 35221 & 0.0909 & A 22 & 0.5195 & 35372 & -151 & 0.4282 & 22740.6910 \\
\hline Oct19 & 36448 & 3.4837 & A24 & 3.4286 & 36429 & 19 & 0.0533 & 377.2532 \\
\hline Nov19 & 35877 & -1.5666 & A 21 & 1.9643 & 37164 & -1287 & 3.5871 & 1656222.1856 \\
\hline Dec19 & 37463 & 4.4207 & A24 & 3.4286 & 37107 & 356 & 0.9501 & 126687.2913 \\
\hline \multirow[t]{2}{*}{$\operatorname{Jan} 20$} & 36911 & -1.4735 & A 21 & 1.9643 & 38199 & -1288 & 3.4892 & 1658636.0900 \\
\hline & & & & & & & 0.8948 & 131324.6120 \\
\hline
\end{tabular}

\section{ACKNOWLEDGEMENTS}

The author is grateful to the Republic of Indonesia's Ministry of Research and Technology/National Research and Innovation Agency (RISTEK-BRIN) who have supported this research. The author wishes to express his gratitude to the anonymous referees for their constructive recommendations and remarks, which helped to improve the manuscript's presentation.

\section{REFERENCES}

[1] Y. Wang, Z. Lin, L. Wang, H. Wang and J. Zhang, "Prediction of Railway Passenger Volume including Waiting Passengers without Tickets," 2020 IEEE 9th Joint International Information Technology and Artificial Intelligence Conference (ITAIC), 2020, pp. 712-716, doi: 10.1109/ITAIC49862.2020.9338840.

[2] W. q. Tian, P. Zhao and K. Qiao, "Railway Freight Volume Forecast Based on GRA-WD-WNN," 20194 th International Conference on Intelligent Transportation Engineering (ICITE), 2019, pp. 84-88, doi: 10.1109/ICITE.2019.8880238.

[3] X. Fuquan and Z. Yi, "Research on Forecast Model and Algorithm of Train Passenger Sending Volume," 2019 11th International Conference on Measuring Technology and Mechatronics Automation (ICMTMA), 2019, pp. 807811, doi: 10.1109/ICMTMA.2019.00182. 
[4] T. Widiyaningtyas, Muladi and A. Qonita, "Use of ARIMA Method To Predict The Number of Train Passenger In Malang City," 2019 International Conference of Artificial Intelligence and Information Technology (ICAIIT), 2019, pp. 359-364, doi: 10.1109/ICAIIT.2019.8834663.

[5] J. Qin, W. Qu, X. Wu and Y. Zeng, "Differential Pricing Strategies of High Speed Railway Based on Prospect Theory: An Empirical Study from China," Sustainability, vol. 11, no. 14, pp. 1-17, 2019, doi: 10.3390/su11143804.

[6] W. Huang and B. Shuai, "A Methodology for Calculating the Passenger Comfort Benefits of Railway Travel," $J$. Mod. Transport., Springer, vol. 26, no. 2, pp. 107-118, 2018, doi: 10.1007/s40534-018-0157-y.

[7] C. H. Aladag, U. Yolcu, E. Egrioglu and A. Z. Dalar, "A New Time Invariant Fuzzy Time Series Forecasting Method Based on Particle Swarm Optimization,” Appl. Soft Comput., vol. 12, no. 10, pp. 3291-3299, 2012, doi: 10.1016/j.asoc.2012.05.002.

[8] M. Stevenson and J. E. Porter, "Fuzzy Time Series Forecasting Using Percentage Change as the Universe of Discourse," World Academy of Science, Engineering and Technology, vol. 3, no. 7, pp. 464-467, 2009, doi: 10.5281/zenodo.1069993.

[9] B. Garg, M. M. S. Beg and A. Q. Ansari, "A new computational fuzzy time series model to forecast number of outpatient visits," 2012 Annual Meeting of the North American Fuzzy Information Processing Society (NAFIPS), 2012, pp. 1-6, doi: 10.1109/NAFIPS.2012.6290977.

[10] E. Bai, W. K. Wong, W. C. Chu, M. Xia and F. Pan, "A Heuristic Time-Invariant Model for Fuzzy Time Series Forecasting," Expert Syst. Appl., vol. 38, no. 3, pp. 2701-2707, 2011, doi: 10.1016/j.eswa.2010.08.059.

[11] E. Egrioglu, C. H. Aladag, U. Yolcu, V. R. Uslu and N. A. Erilli, "Fuzzy Time Series Forecasting Method Based on Gustafson-Kessel Fuzzy Clustering," Expert Syst. Appl., vol. 38, no. 8, pp. 10355-10357, 2011, doi: 10.1016/j.eswa.2011.02.052.

[12] E. Egrioglu, C. H. Aladag and U. Yolcu, "Fuzzy Time Series Forecasting with a Novel Hybrid Approach Combining Fuzzy C-Means and Neural Networks," Expert Syst. Appl., vol. 40, no. 3, pp. 854-857, 2013.

[13] F. J. J. D. Santos and H. D. A. Camargo, "Preprocessing in Fuzzy Time Series to Improve the Forecasting Accuracy," 2013 12th International Conference on Machine Learning and Applications, 2013, pp. 170-173, doi: 10.1109/ICMLA.2013.185.

[14] J. Chang and Chung-Chi Liu, "A fuzzy time series model based on N-th Quantile Discretization Approach for TAIEX forecasting," 2013 5th International Conference on Knowledge and Smart Technology (KST), 2013, pp. 510, doi: 10.1109/KST.2013.6512778.

[15] L. Wang, X. Liu and W. Pedrycz, "Effective Intervals Determined by Information Granules to Improve Forecasting in Fuzzy Time Series," Expert Syst. Appl., vol. 40, no. 14, pp. 5673-5679, 2013, doi: 10.1016/j.eswa.2013.04.026.

[16] P. Singh and B. Borah, "An Efficient Time Series Forecasting Model Based on Fuzzy Time Series," Eng. Appl. Artif. Intell., vol. 26, no. 10, pp. 2443-2457, 2013, doi: 10.1016/j.engappai.2013.07.012.

[17] S. M. Chen and C. D. Chen, "Handling Forecasting Problems Based on High-Order Fuzzy Logical Relationships," Expert Syst. Appl., vol. 38, no. 4, pp. 3857-3864, 2011, doi: 10.1016/j.eswa.2010.09.046.

[18] S. M. Chen and K. Tanuwijaya, "Fuzzy Forecasting Based on High-Order Fuzzy Logical Relationships and Automatic Clustering Techniques," Expert Syst. Appl., vol. 38, no. 12, pp. 15425-15437, 2011, doi: 10.1016/j.eswa.2011.06.019.

[19] S. S. Gangwar and S. Kumar, "Partitions Based on Computational Method for High-Order Fuzzy Timeseries Forecasting," Expert Syst. Appl., vol. 39, no. 15, pp. 12158-12164, 2012, doi: 10.1016/j.eswa.2012.04.039.

[20] V. R. Uslu, E. Bas, U. Yolcu and E. Egrioglu, "A Fuzzy Timeseries Approach Based on Weights Determined by the Number of Recurrences of Fuzzy Relations," Swarm Evol. Comput., vol. 15, pp. 19-26, 2014, doi: 10.1016/j.swevo.2013.10.004.

[21] W. Qiu, X. Liu and H. Li, "A Generalized Method for Forecasting Based on Fuzzy Timeseries," Expert Syst. Appl., vol. 38, no. 8, pp. 10446-10453, 2011, doi: 10.1016/j.eswa.2011.02.096.

[22] N. Y. Wang and S. M. Chen, "Temperature Prediction and TAIFEX Forecasting Based on Automatic Clustering Techniques and Two-Factors High-Order Fuzzy Timeseries," Expert Syst. Appl., vol. 36, no. 2, 2143-2154, 2009, doi: 10.1016/j.eswa.2007.12.013.

[23] S. Li and Y. Cheng, "A Stochastic HMM-Based Forecasting Model for Fuzzy Time Series," in IEEE Transactions on Systems, Man and Cybernetics, Part B (Cybernetics), vol. 40, no. 5, pp. 1255-1266, Oct. 2010, doi: 10.1109/TSMCB.2009.2036860.

[24] C. H. Cheng, L. Y. Wei, J. W. Liu and T. L. Chen, "OWA-Based ANFIS Model for TAIEX Forecasting," Economic Modelling, vol. 30, pp. 442-448, 2013, doi 10.1016/j.econmod.2012.09.047.

[25] L. Y. Wei, C. H. Cheng and H. H. Wu, "A Hybrid ANFIS Based on N-Period Moving Average Model to Forecast TAIEX Stock,” Appl. Soft Comput., vol. 19, pp. 86-92, 2014, doi: 10.1016/j.asoc.2014.01.022.

[26] Q. Cai, D. Zhang, B. Wu and S. C. H. Leung, "A Novel Stock Forecasting Model Based on Fuzzy Time Series and Genetic Algorithm,” Proc. Comput. Sci., vol. 18, pp. 1155-1162, 2013, doi: 10.1016/j.procs.2013.05.281.

[27] Q. Cai, D. Zhang, W. Zheng and S. C. H. Leung, "A New Fuzzy Time Series Forecasting Model Combined with Ant Colony Optimization and Auto-Regression," Knowl- Based Syst., vol. 74, pp. 61-68, 2015, doi: 10.1016/j.knosys.2014.11.003.

[28] S. Cheng, S. Chen and W. Jian, "A Novel Fuzzy Time Series Forecasting Method Based on Fuzzy Logical Relationships and Similarity Measures," 2015 IEEE International Conference on Systems, Man, and Cybernetics, 2015, pp. 2250-2254, doi: 10.1109/SMC.2015.393.

[29] S. H. Cheng, S. M. Chen and W. S. Jian, "Fuzzy Time Series Forecasting Based on Fuzzy Logical Relationships and Similarity Measures," Information Sciences, vol. 327, pp. 272-287, 2016, doi: 10.1016/j.ins.2015.08.024. 
[30] S. Chen and C. Chen, "TAIEX Forecasting Based on Fuzzy Time Series and Fuzzy Variation Groups," in IEEE Transactions on Fuzzy Systems, vol. 19, no. 1, pp. 1-12, Feb. 2011, doi: 10.1109/TFUZZ.2010.2073712.

[31] S. Chen, H. Chu and T. Sheu, "TAIEX Forecasting Using Fuzzy Time Series and Automatically Generated Weights of Multiple Factors," in IEEE Transactions on Systems, Man, and Cybernetics - Part A: Systems and Humans, vol. 42, no. 6, pp. 1485-1495, Nov. 2012, doi: 10.1109/TSMCA.2012.2190399.

[32] S. Chen, G. M. T. Manalu, J. Pan and H. Liu, "Fuzzy Forecasting Based on Two-Factors Second-Order FuzzyTrend Logical Relationship Groups and Particle Swarm Optimization Techniques," in IEEE Transactions on Cybernetics, vol. 43, no. 3, pp. 1102-1117, June 2013, doi: 10.1109/TSMCB.2012.2223815.

[33] S. Chen and S. Chen, "Fuzzy Forecasting Based on Two-Factors Second-Order Fuzzy-Trend Logical Relationship Groups and the Probabilities of Trends of Fuzzy Logical Relationships," in IEEE Transactions on Cybernetics, vol. 45, no. 3, pp. 391-403, March 2015, doi: 10.1109/TCYB.2014.2326888.

[34] Y. Cheng and S. Li, "Fuzzy Time Series Forecasting With a Probabilistic Smoothing Hidden Markov Model," in IEEE Transactions on Fuzzy Systems, vol. 20, no. 2, pp. 291-304, April 2012, doi: 10.1109/TFUZZ.2011.2173583.

[35] S. Xihao and L. Yimin, "Average-Based Fuzzy Timeseries Models for Forecasting Shanghai Compound Index," World Journal of Modelling and Simulation, vol. 4, no. 2, pp. 104-111, 2008.

[36] C. Kai, F. Fang-Ping and C. Wen-Gang, "Notice of Retraction: A Novel Forecasting Model of Fuzzy Time Series Based on K-means Clustering," 2010 Second International Workshop on Education Technology and Computer Science, 2010, pp. 223-225, doi: 10.1109/ETCS.2010.249.

[37] H. T. Liu and M. L. Wei, “An Improved Fuzzy Forecasting Method for Seasonal Time Series," Expert Syst. Appl., vol. 37, no. 9, pp. 6310-6318, 2010, doi: 10.1016/j.eswa.2010.02.090.

[38] P. Singh, “An Efficient Method for Forecasting Using Fuzzy Time Series,” Comput. Sci., IGI-Global, pp. 287-304, 2017, doi: 10.4018/978-1-5225-0914-1.ch013.

[39] S. M. Chen and K. Tanuwijaya, "Multivariate Fuzzy Forecasting Based on Fuzzy Time Series and Automatic Clustering Techniques," Expert Syst. Appl., vol. 38, no. 8, pp. 10594-10605, 2011, doi: 10.1016/j.eswa.2011.02.098.

[40] S. M. Chen and B. D. H. Phuong, "Fuzzy Time Series Forecasting Based on Optimal Partitions of Intervals and Optimal Weighting Vectors," Knowl- Based Syst., vol. 118, pp. 204-216, 2017, doi: 10.1016/j.knosys.2016.11.019.

[41] Y. L. Huang, S. J. Horng, T. W. Kao, R. S. Run, J. L. Lai, R. J. Chen, I. H. Kuo and M. K. Khan, "An Improved Forecasting Model Based on The Weighted Fuzzy Relationship Matrix Combined with a PSO Adaptation for Enrollments," International Journal of Innovative Computing, Information and Control, vol. 7, no. 7a, pp. 40274045, 2011.

[42] K. H. Huarng and T. H. K. Yu, "Modeling Fuzzy Time Series with Multiple Observations," Iternational Journal of Innovative Computing, Information and Control, vol. 8, no. 10b, pp. 7415-7426, 2012.

[43] T. A. Jilani, S. M. A. Burney and C. Ardil, "Fuzzy Metric Approach for Fuzzy Time Series Forecasting Based on Frequency Density Based Partitioning," International Journal of Computer and Information Engineering, WASET, vol. 4, no. 7, pp. 1194-1199, 2010, doi: 10.5281/zenodo.1077541.

[44] P. Saxena, K. Sharma and S. Easo, "Forecasting Enrollments Based on Fuzzy Time Series with Higher Forecast Accuracy Rate," Int. J. Computer Technology \& Applications (IJACTA), vol. 3, no. 3, pp. 957-961, 2012, doi: 10.1.1.643.4986.

[45] Q. Song and B. S. Chissom, "Fuzzy Time Series and Its Models," Fuzzy sets and Systems, vol. 54, no. 3, 269-277, 1993, doi: 10.1016/0165-0114(93)90372-O.

[46] T. A. Jilani, S. M. A. Burney and C. Ardil, "Multivariate High Order Fuzzy Time Series Forecasting for Car Road Accidents," International Journal of Computer and Information Engineering, WASET, vol. 2 no. 6, pp. 2038-2043, 2008, doi: 10.5281/zenodo.1085455.

[47] M. G. Chung and S. K. Kim, "Efficient Jitter Compensation Using Double Exponential Smoothing," Information Sciences, vol. 227, pp. 83-89, 2013, doi: 10.1016/j.ins.2012.12.008.

[48] L. Wu, S. Liu and Y. Yang, "Grey Double Exponential Smoothing Model and Its Application on Pigprice Forecasting in China," Appl. Soft Comput., vol. 39, pp. 117-123, 2016, doi: 10.1016/j.asoc.2015.09.054.

[49] D. Barrow, N. Kourentzes, R. Sandberg, and J. Niklewski, "Automatic robust estimation for exponential smoothing: Perspectives from statistics and machine learning," Expert Syst. Appl., vol. 160, pp. 1-14, 2020, doi: 10.1016/j.eswa.2020.113637.

[50] C. C. Holt, "Forecasting Seasonals and Trends by Exponentially Weighted Moving Averages," International Journal of Forecasting, vol. 20, no. 1, pp. 5-10, 2004, doi: 10.1016/j.ijforecast.2003.09.015.

\section{BIOGRAPHIES OF AUTHORS}

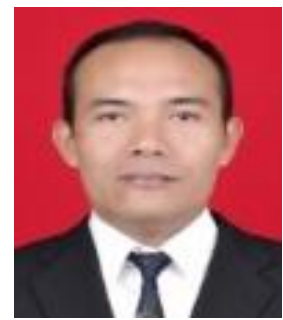

Solikhin is currently works as Senior Lecturer in the Department of Informatics Engineering, STMIK Himsya, Semarang, Indonesia. He received her Bachelor degree (AKI University), Master degree (Diponegoro University). His experience and areas of research interest focus and scope on computer science, business intelligence, decision support system, information system. 

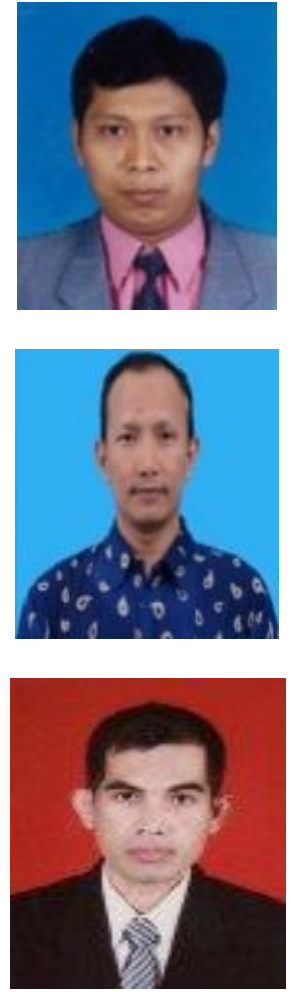

Septia Lutfi is currently works as Senior Lecturer in the Department of Informatics Engineering, STMIK Himsya, Semarang, Indonesia. He received her Bachelor degree (AKI University), Master degree (Dian Nuswantoro University), His experience and areas of research interest focus and scope on computer science, computer engineering and informatics: software engineering, programming, data engineering.

Purnomo is currently works as Associate Professor at the Faculty of Engineering, University of Muhammadiyah Semarang, Indonesia. His qualification as below: bachelor degree (Diponegoro University), master degree (Gadjah Mada University), Dr. (Brawijaya University). His experience and areas of research interest focus and scope on mechanical engineering and technology: applied engineering, engineering science and technology, materials science and engineering.

Hardiwinoto is currently works as Senior Lecturer at the Faculty of Economics, University of Muhammadiyah Semarang, Indonesia. He received her bachelor degree, master degree, and Dr. in Diponegoro University. His experience and areas of research interest focus and scope on economics: contemporary business, economics and law. 